\title{
JURIDIFICAÇÃO E DESJURIDIFICAÇÃo EM HABERMAS
}

\author{
Celso F. Rocha de Barros
}

RESUMO: O Direito é uma entidade conceitual singular dentro da obra de Habermas: por um lado, ele é uma mediação entre sistema e mundo da vida; por outro, ele articula questões que constituem o background social da Teoria da Af̧ão Comunicativa, como a crise do Welfare State e a Crítica pós-estruturalista da Razão. Neste artigo procuramos comparar duas intervenções de Habermas sobre o Direito: a análise da juridificação na Teoria da Ação Comunicativa e a discussão sobre a desformalização da lei nas Tanner Lectures. Como conclusão, reafirmamos a importância e a singularidade da discussão sobre o Direito, e procuramos ligá-la à discussão sobre a globalização.

PALAVRAS-CHAVE: Habermas; Direito; desformalização; juridificação; globalização.

Com a publicação de Betveen Facts and Norms, ${ }^{1}$ finalmente os leitores de Habermas podem contar com uma apresentação sistemática das teses habermasianas sobre o Direito Moderno. O objetivo deste texto é oferecer uma demonstração da importância teórica da problemática do Direito para o desenvolvimento da teoria social habermasiana, bem como para o de seus desdobramentos normativos, a partir de textos anteriores a esta obra.

\footnotetext{
1 Betveen Facts and Norms é o titulo em inglês que aparece em algumas resenhas recentes; no entanto, este livro não havia sido traduzido para o inglês até o envio deste artigo para publicação.
} 
Inicialmente apresentaremos as duas tematiza.ções mais conhecidas do Direito na obra de Habermas: a crítica da juridificação na Teoria da Aşão Comunicativa e a análise da desformalização da Lei no Welfare State desenvolvida nas Tanner Lectures. Como conclusão, procuraremos demonstrar que a posição singular do Direito dentro da teoria habermasiana dá a estas análises o status de entradas privilegiadas para certos problemas caros a Habermas.

Não é o nosso objetivo aqui discutir questões clássicas da Teoria do Direito. Isto se deve a uma série de fatores, mas os principal é que esses problemas são colocados apenas implicitamente nas obras aqui analisadas. Habermas dedicou um livro especificamente à questão do Direito, em que esperamos encontrar estas questões mais clirramente discutidas. No entanto, esta obra só se encontra disponível em alemão. Desta forma, nos abstemos de discutir pontos ainda não claramente formulados, pois eventuais discordâncias não poderiam ser claramente discutidas.

\section{A JURIdificaÇão DENTRO da TEORIA Da AÇĀo COMUNICATIVA}

A Teoria da Modernidade desenvolvida na Teoria da Ação Comunicativa (Habermas, 1987) pode ser descrita, de maneira apressada, como se segue: uma apropriação crítica da análise weberiana segundo uma perspectiva que insere a análise marxista frankfurtiana no quadro de uma teoria da comunicação que enfatiza o potencial democrático da conduta racional; e a contraposição desta reformulação ao pesadelo weberiano-frankfurtiano de um mundo totalmente administrado, personificado na teoria dos sistemas. O conflito termina com o diagnóstico de um impasse, e a proposição de uma solução democratizante radical.

Ao discutir a análise do processo de racionalzação desenvolvido na cultura ocidental, Habermas adota uma perspectiva evolucionária de 
tipo específico: trata-se de descrever uma história interna ${ }^{2}$ da razão. Admitindo que não se pode comparar as visões de mundo segundo suas racionalidades internas, sustenta contudo que há visões de mundo que favorecem procedimentos racionais; ${ }^{3}$ há várias formulações desta tese na Teoria: em termos estritamente estruturalistas, isto é, através da comparação entre o pensamento mítico e o pensamento racional; em termos popperianos, diferenciando-se sociedades abertas e fechadas; em termos de autonomia entre sistema e mundo da vida; em analogia com a psicologia do desenvolvimento, etc.; em função de nosso interesse específico, centraremos nossa atenção no desenvolvimento das moralidades e no desacoplamento entre sistema e mundo da vida.

Segundo Ingram (1987, p.144), pode-se estabelecer uma analogia entre os estágios do desenvolvimento moral e os estágios do desenvolvimento da competência comunicativa. Para Mead, este último se dá em três estágios: ${ }^{4}$ no primeiro, os papéis de quem ouve e de quem fala são definidos exclusivamente em referência a situações concretas, como por exemplo, na maioria das situações que envolvem a criança e seus pais. No segundo, adquire-se uma noção de identidade étnica, nacional ou

${ }^{2}$ Essa distinção é importante na medida em que diferencia a perspectiva habermasiana, por exemplo, da adotada por Michel Foucault, que aliás é quem introduz a distinção entre história interna da verdade (que se coloca do ponto de vista de desenvolvimentos cognitivos, como na história da ciência) e história externa da verdade (que procura as lutas sociais em cujo contexto se dá a produção dos saberes, concebendo, como Nietzsche, a verdade como "uma faísca entre duas espadas"). No entanto, a distinção não deve ser levada longe demais, pois Habermas não limita sua análise ao aspecto cognitivo, mas associa, no sentido forte, esse desenvolvimento a um desenvolvimento moral. Para a apresentação desta distinção, ver Foucault (1996).

${ }^{3}$ Habermas (1987) define uma ação racional como aquela que levanta em seu favor uma pretensão de validade, seja em termos de adequação teórico-estratégica, seja em termos de adequação moral, scja em termos de sinceridade individual, pretensão esta que pode ser criticada por argumentos válidos.

tDeve-se refletir a respeito do status teórico destes estágios: se são etapas cronologicamente necessárias ou tipos ideais que na realidade podem se sobrepor: isso é importante na medida em que podemos nos perguntar, por exemplo, sobre as possibilidades $\mathrm{dc}$ fenômenos morais pré-convencionais ou convencionais ocorrerem na modernidade. 
cosmopolita, mas estas noções são atribuídas ao indivíduo pelos outros. No terceiro, através da aquisição de responsabilidade sobre sua própria identidade, o adolescente pode enfim assumir uma postura reflexiva - crítica - com relação aos papéis assumidos.

Analogamente, o desenvolvimento moral passa por três estágios: o pré-convencional, baseado no sistema organizativo do parentesco, organizase em termos de obediência e punição ou segundo o princípio de reciprocidade imediata. Não há autoridade formalmente constituída: a arbitragem visa apenas restaurar uma situação anterior (e.g., estabelecer uma indenização por um dano causado), e não se baseia em um compromisso entre as partes no sentido de acatar a decisão do árbitro seja qual for. Em outros termos, o objetivo do procedimento jurídico é compensar as conseqüências da ação (através de procedimentos rituais de reparação ou vingança), e não julgar sua moralidade. No segundo estágio, o convencional, a moralidade das ações já é julgada independentemente das conseqüências, e normalmente referida ao crime contra o soberano. No terceiro, o pós-convencional, a atitude reflexiva com relação às normas sociais é institucionalizada através da formalização jurídica, que confere às normas sociais o status de leis democraticamente instituídas e questionáveis segundo procedimentos pré-definidos, ao mesmo tempo em que enraiza o sistema legal em uma moralidade altamente favorável ao desenvolvimento racional, em que os valores da autonomia e a ética da comunicação legitimam a estrutura de poder.

Os autores da Escola de Frankfurt enfatizaram em suas análises o quanto esse desenvolvimento ideal havia sido distorcido pelo desenvolvimento do capitalismo, do estado burocrático e da indústria cultural. Em conseqüência destes fenômenos as decisões políticas são cada vez mais transferidas da esfera pública para órgãos burocráticos, a autonomia artística é sacrificada em favor do mercado e a criatividade individual é submetida à disciplina da produção de massa. 
Habermas chama a atenção, em seu debate com Foucault, 5 para uma questão que deve ser colocada a quem quer que se proponha fazer considerações de tipo frankfurtiano: de que ponto de vista podemos nos colocar para criticar a razão sem recorrer a valores reacionários? Pois tanto a democracia - que é contraposta ao Estado burocrático - quanto as utopias de libertação do trabalho - que baseiam a crítica do capitalismo - quanto a arte romântica - que se opõe à massificação cultural - só se desenvolveram na sociedade ocidental, como conseqüências diretas do processo de racionalização. Assim, se é verdade que a razão pode voltar-se contra si mesma e tornar-se totalitária (Habermas não nega essa possibilidade), só ela pode ser democrática, em conseqüência dos desenvolvimentos pós-convencionais e ético-comunicativos descritos acima. Os fenômenos criticados pelos frankfurtianos devem ser encarados como desenvolvimentos particulares da racionalização social, como a história externa da racionalidade, isto é, como distorções causadas pelo meio social em que este processo se desenvolveu, a saber, o capitalismo tardio. ${ }^{6}$ Apesar de estarem equipados com um instrumental marxista que lhes permitiu identificar esta relação, os frankfurtianos se mantiveram presos a uma descrição da racionalização em termos weberianos, o que os impediu de perceber o potencial democrático da racionalização.

Weber analisou o processo de racionalização em praticamente todas as esferas da sociedade ocidental, e se colocou como motivo central de sua obra a pesquisa da peculiaridade desta sociedade que a fez ser o único palco destes desenvolvimentos.

Em seus estudos sobre a ética econômica das religiões universais, Weber compara o cristianismo, o budismo e o confucionismo segundo os seguintes critérios: a atitude frente ao mundo material (negação ou afirmação) e o caráter mais ou menos personalizado da divindade (Deus

5Para uma apresentação deste debate, ver Kelley (1994).

'Para uma apresentação do conceito de capitalismo tardio, ver Habermas (1994). 
como pessoa ou como ordem cósmica impessoal); sob esta perspectiva, o cristianismo favorece a racionalização na medida $\mathrm{em}$ que é um dever perante Deus (com quem se faz um pacto) ganhar controle sobre o mundo (que é visto como um fruto da queda, esperando a redenção pela cristandade). A atitude meramente negativa perante ao mundo pode implicar em fuga (como no budismo); uma atitude afirmativa com relação ao mundo, como a do confucionismo, produz uma ética de adaptação; é somente a combinação singular judaico-cristã que favorece a racionalização. Habermas aceita esta análise em suas linhas gerais, mas critica Weber por não considerar a cultura grega $\mathrm{em}$ suas análises, uma vez que esta serviria tanto para enfatizar a importância da intuição teórica na racionalização quanto como exemplo da insuficiência, no que concerne às condições necessárias à racionalização, de uma concepção personalista de Deus (que pode implicar em adesão incondicional à vida, como nos gregos).

O momento em que esta ética religiosa atinge o ápice de seu potencial racionalizante é o protestantismo, quando a doutrina da predestinação de Calvino proclama a separação entre os atos virtuosos em vida $\mathrm{e}$ a salvação; ao mesmo tempo, fornece um critério para reconhecer quem são os predestinados: o sucesso material nesta vida; o desprezo pela caridade, a valorização do trabalho por si mesmo e não apenas pelos bens que pode proporcionar, foram valores importantíssimos na formação do espírito empresarial moderno. Mas Weber afirma, na conclusão de seu estudo sobre a ética protestante, que o desenvolvimento posterior do capitalismo tornou o protestantismo desnecessário (funcionalmente?), e criou mecanismos (sistêmicos?) que permitem a autoreprodução capitalista. Neste contexto, Weber temia um esvaziamento da modernidade de qualquer caráter moral, e o predomínio dos "especialistas sem espírito" e dos "sensualistas sem coração" (Weber, 1989, p.131).

Segundo Habermas, esta análise tem o mérito de colocar corretamente o principal problema da época: a submersão dos valores dentro do sistema econômico e administrativo. Mas seu excessivo pessimismo 
era devido à exclusão analítica de alguns aspectos importantes: por um lado, do fato de que a razão tem, intrinsecamente, um potencial democratizante e se enraíza em certos valores pós-convencionais; por outro, que os fenômenos descritos por Weber eram devidos a encarnações específicas da racionalização no momento de constituição do capitalismo tardio.

Durkheim já havia afirmado que a sociedade em que os indivíduos se associam livremente por contratos não está solta no vazio moral, mas também enraíza-se em valores que fazem com que, por exemplo, os contratos sejam honrados. A teoria da comunicação de Mead, por outro lado, supõe um certo conjunto de significados que não é problematizado na discussão e que, por isso, possibilitam o agir comunicativo. Este é o momento em que Habermas introduz as noções de Sistema e Mundo da Vida, bases de sua conceituação do mundo moderno. Segundo Ingram

“(...) o sistema integra diversas atividades, de acordo com os objetos de adaptação à sobrevivência econômica e política, mediante a regulagem das consequiências não-pretendidas da ação estratégica por mecanismos de mercado ou burocráticos que limitam o escopo das decisões voluntárias. O mundo vivo, de outro lado, contribui para manter a identidade social e do individuo ao organizar a ação em torno de interesses compartilhados, de modo a alcançar um acordo sobre titulos de validade que são criticáveis" (Ingram, 1987, p.153).

É característico de uma sociedade racional que os sistemas produtivo e administrativo se autonomizem frente à tradição. Em sociedades de moralidade convencional as atividades relacionadas à reprodução material e à administração política se encontram imersas na tradição. É uma condição do progresso técnico e da administração formal que estas considerações morais sejam deixadas de lado. Assim, o sistema econômico e o sistema administrativo (intimamente ligados no capitalismo tardio) se autonomizam. Isto não implica, no entanto, que estes sistemas passem 
a existir no "vazio moral". Ao mesmo tempo que o sistema, autonomizase um mundo da vida (aquilo que não se problematiza em uma discussão por ser o consenso mínimo que a possibilita) racionalizado, isto é, a moralidade torna-se pós-convencional. ${ }^{7}$

Essa interpretação dual da sociedade moderna não é, no entanto, livre de dificuldades. Ingram critica Habermas por sua

"tendência a identificar cada um dos termos com instituições determinadas (...). O mundo vivo e o sistema são vistos como pertencentes a reinos da sociedade absolutamente separados: as familias e as esferas de acesso público - cultural, social e politico - ao mundo vivo; as empresas e os órgãos do Estado ao sistema.

As muitas dificuldades trazidas por essa interpretação derivam do fato de que o mundo vivo e o sistema têm a ver com reinos absolutamente distintos. No entanto, está claro que não se pode dissociar as funcões reprodutivas materiais da familia, ou as funcões reprodutivas simbólicas da comunidade empresarial"'(Ingram, 1987, p.153).

Ora, sob este ponto de vista, a discussão sobre o Direito é interessante na medida em que o Direito é considerado por Habermas o momento do enraizamento do sistema no mundo da vida. A discussão, presente no final da Teoria da Ação Comunicativa, sobre a juridificação dá margem a novas discussões, que podem relativizar a idéia de separação estanque entre as duas esferas.

Habermas retoma a discussão weberiana da perda de sentido, bem como a discussão marxista a respeito da reificação, como colonizą̧ão do mundo da vida, ou seja, o momento em que os media reguladores do sistema passam a regular também a produção de sentido. $A$ indústria cultu-

'É esta moralidade que garante, por exemplo, o respeito aos contratos firmados, ao mesmo tempo em que permite ao movimento operário levantar criticas à forma do contrato.

${ }^{8}$ Os media são, para Parsons e a sociologia sistêmica, elementos impessoais de regulação sistêmica, como o dinheiro $\mathrm{c}$ o poder.

Temáticas, Campinas, 4(8):119-141, jul./dcz. 1996 
ral seria um exemplo de colonização do mundo da vida; mas o exemplo desenvolvido por Habermas no final do livro é extremamente significativo para nossos propósitos: a juridificação.

Segundo sua análise, o Direito, que é o enraizamento do sistema no mundo da vida, o é enquanto instituifão, que, como veremos no tópico seguinte, só pode se autonomizar na presença de instituições democráticas. Mas ele também é media, ${ }^{9}$ e assim provoca a colonização do mundo da vida ao atomizar os indivíduos frente ao Estado, quando codifica suas relações dentro de mecanismos burocráticos de decisão e nega assim a situação ideal de comunicação que pressupõe os participantes se relacionando e livres da ação do poder. Um exemplo desta colonização seria a formação de um Direito de família que não tem como se furtar de raciocinar em termos de imperativos funcionais, como podemos ver no exemplo das decisões relativas à guarda de crianças em caso de divórcio: a pesquisa empírica mostra que o bem-estar material da criança é muito mais valorizado do que seu bem-estar psicológico; a alternativa de deixar a decisão a cargo de psicólogos traz em si outra dificuldade: submete a vida familiar a um tipo de decisão técnica característica da burocracia. Desta forma, esvazia-se a família enquanto espaço de comunicação e socialização.

Neste ponto parecemos estar próximos das análises de cunho pósestruturalista semelhante às de Foucault: poderíamos colocar a questão em termos de transferência de poder da figura do pai para a administração impessoal do Estado. Além do mais, algumas formulações de Habermas poderiam sugerir que o Direito é apenas um dispositivo de poder, a ser criticado em nome de reivindicações de caráter comunitário. No entanto, como veremos no tópico a seguir, a visão de Habermas é um pouco mais complexa: ele reconhece que se pode sacrificar a forma-

'Nossa análise subseqüente não vai se aprofundar na distinção entre o Direito enquanto media e enquanto instituição, visto que em entrevista recente, Habermas sugere a necessidade de sua revisão (Habermas, 1995). 
lização da lei em favor de reivindicações de caráter comunitário; mas estabelece como limite a essa desformalização os princípios da moral pósconvencional.

\section{A DESJURIDIFICAÇĀO NAS TANNER LECTURES ${ }^{10}$}

Ao mesmo tempo em que temia os perigos da racionalização, Weber se colocava contra o que chamava de materializąão do Direito, um processo iniciado com a constituição do Estado interventor característico do capitalismo moderno, que por um lado intervém ativamente na economia através de mecanismos variados e por outro compensa as desigualdades distributivas provocadas pelos mecanismos de mercado através de políticas de bem-estar. Weber tem como referência positiva o Estado Liberal Clássico: uma legislação coerente e clara (formal), elaborada e administrada por experts, garante a previsibilidade das ações individuais. Este modelo é claramente o do Direito Civil orientando a formulação de contratos na atividade empresarial, mas uma associação mecânica entre Direito formal e interesse capitalista é problemática, como frisou, por exemplo, Neumann. ${ }^{11} \mathrm{O}$ novo Estado interventor coloca em

${ }^{10} \mathrm{As}$ Tanner Lectures_constituem duas palestras proferidas por Habermas com os títulos "How is Legitimacy Possible on the Basis of Legality?" $\mathrm{e}$ "On the idea of the Rule of Law"; curiosamente, as palestras têm exatamente a mesma estrutura da Teoria. uma crítica a Weber a partir da afirmação de uma moralidade pós-convencional; e uma crítica à teoria dos sistemas baseada nesta mesma idéia. No entanto, a relação entre sistema e mundo da vida são concebidas de maneira bem diferentes no final da exposição. Para este trabalho, contamos com uma versão manuscrita com o título de Lan and Morality: two lectures, em 1988, ano de elaboração do artigo de Scheuerman, os dois textos estavam para ser publicados com o nome de Tanner Lectures.

"1F.Neumann foi um teórico politico de inspiração frankfurtiana. Sua análise do sistema político nazista levou-o a criticar severamente a desformalização do Direito; identificando ao Direito formal possibilidades de garantia da autonomia individual, propõe a radicalização da formalização no sentido de colocar em xeque as assimetrias sociais características do capitalismo. Para uma comparação entre Habermas e Neumann, ver Scheuerman (1988 e 1994).

Temáticas, Campinas, 4(8):119-141, jul./dez. 1996 
xeque estes princípios na medida em que estabelece figuras legais como "interesse nacional" ou "justiça social" para justificar intervenções contingentes. Estas figuras são suficientemente vagas para assegurar alto grau de capacidade discricionária ao legislador e ao jurista, ameaçando-se assim o princípio da previsibilidade. Novamente não podemos identificar a crítica da desformalização exclusivamente com o interesse capitalista: entre os proponentes da desformalização estavam teóricos do nazismo, para quem o estado não precisava de leis, mas sim de medidas. Assim, devemos levar a sério a afirmação de que a formalização da lei é uma garantia da liberdade; no entanto, devemos reconhecer que o Welfare State proporcionou conquistas inéditas em termos de solidariedade social. Uma maneira de abordar a questão seria colocá-la nos seguintes termos: ou devemos abandonar os princípios do autogoverno democrático, ou a idéia de Direito. A argumentação de Habermas vai no sentido de mostrar que há uma formulação alternativa para esta questão, a saber: em que contexto a desformalização da lei serve aos princípios da moral pósconvencional? Isto é, o quanto de formalização é necessário à democracia, e o quanto de moralidade é necessário à Lei?

A idéia da desformalização tem sido confirmada por desenvolvimentos recentes, de natureza diferente das "medidas" do Estado regulador da época de Weber. Entre eles poderíamos citar: a reflexidade das leis, que delega aos contendentes competência negociativa, como se verifica em acordos jurídicos informais e negociações coletivas; a marginalizafãa, que faz com que a capacidade da lei se tornar um vínculo social forte seja reduzida; a ação de imperativos funcionais (relacionados às necessidades do mercado ou do Estado), que se impõe sobre a atividade jurídica, sem necessariamente se integrar em um programa conscientemente elaborado, e que submete as atividades jurídicas e legislativas a necessidades do mercado ou da burocracia; e conflitos entre moralidade e a lei positiva, que se relaciona a uma reivindicação mais intensa de legitimidade da lei e à 
contraposição entre a lei positiva e uma lei "correta", como nos casos de desobediência civil. ${ }^{12}$

Seguindo sua orientação geral de opor racionalidade formal a racionalidade substantiva, Weber se recusa a admitir um fundamento moral para a lei racional. No entanto, Habermas irá demonstrar que isto pode esvaziar o conceito de dominação legal, na medida em que as tentativas de Weber de derivar a legitimidade da legalidade exclusivamente de suas características formais tem escassa possibilidades de sucesso: uma breve olhada nos fortíssimos movimentos de trabalhadores do século XIX mostra que o Estado Burguês clássico tem grandes dificuldades de se legitimar por si só.

Habermas procura demonstrar que a legalidade só pode se legitimar através de seu enraizamento em uma moralidade pós-convencional, e, portanto, reflexiva: por um lado, através de uma racionalidade procedimental que garante que os princípios da democracia sejam respeitados no momento de elaboração legislativa, e que os argumentos apresentados nestas discussões reinvindiquem para si validade universal; por outro, que nas discussões jurídicas a situação ideal de uma comunicação livre de poder seja um pressuposto, que se distribua igualitariamente o ônus da prova e as obrigações de justificação e que a aplicação das normas seja sensível ao contexto.

Habermas cita três teorias já formuladas que se baseiam na justificação pelo procedimento, sem discuti-las: a de Rawls (contratualista), a de Kohlberg (baseado no conceito de "role-taking" de Mead) e a de Habermas e Apel, que sustentam que a argumentação moral é o procedimento adequado à formação de vontades racionais; no entanto, acrescenta:

"Entretanto, essas abordagens devem se perguntar se suas formas de questionamento não são irremediavelmente ingênuas, tendo em vista a

12Para uma análise da desobediência civil, ver Habermas (1988). 
complexidade rapidamente crescente de nossa sociedade. Se nós considerarmos a crítica desenvolvida pelo Realismo Legal e boje radicalizada pelos Critical Legal Studies, toda investigafão normativa que observa o Primado da Lei de uma perspectiva interna e, por assim dizer, toma-lhe ao pé da letra, parece cair em um idealismo impotente"13 (Habermas, s.d.).

Por isso, em sua palestra seguinte Habermas se desloca da perspectiva moral para a perspectiva da teoria social. Como de hábito, Habermas começa sua argumentação com uma crítica a Luhman. Segundo Habermas, a interpretação sistêmica da lei pode ser interpretada assim:

'Primeiro, a qualidade deontológica das regras vinculantes é redefinido de tal forma que torna-se passivel de uma análise puramente funcional. Segundo, o modelo positivista de Lei é tradurido no modelo funcionalista de um Sistema Legal que se diferenciou de outros subsistemas sociais e se tornou completamente autônomo. E terceiro, a legitimidade da legalidade é explicada como um tipo de sofisticada autoilusão requerida pela natureza paradoxal do código legal e alcançada pelos meios do próprio sistema legal"14 (Habermas, s.d.).

A essência do argumento funcionalista consiste, portanto, em negar qualquer conteúdo de racionalidade ao sistema legal. A moralidade da lei torna-se apenas uma auto-ilusão requerida por necessidades sistêmi-

${ }^{13}$ No original: "However, all of these approaches must face the question of wether their mode of questioning is not hopelessly naive in view of the rapidly growing complexity of our society. If we consider the critique developed by Legal realism and further radicalized today by Critical Legal Studies, every normative investigation that observes the rule of law from an internal perspective and, so to speak, takes it at its word, seems to fall into an impotent idealism.".

${ }^{14}$ No original: " First, the deontological quality of binding rules is redefined so that it is amenable to a purely functional analysis. Second, the positivist interpretation of law is translated into the functionalist model of a legal system that has differentiated itself off from other social subsystems and became completely autonomous. And thirdly, the legitimacy of legality is explained as a kind of sophisticated self-deception required by the paradoxical nature of the legal code and achieved by the very means of the legal system itself." 
cas. Ora, a simples existência de movimentos de crítica ao direito como o Critical Legal Studies ${ }^{15}$ já torna esta hipótese implausível, a menos que se admita que o sistema é altamente ineficiente em reproduzir as condições de sua autonomia; Habermas redefine a autonomia da lei, em oposição à noção de sistema autopoiético, como um fenômeno que se desenvolve dentro das seguintes condições: desde que a lei não entre em contradição com o núcleo moral do sistema legal; e desde que as reinvindicações extra-jurídicas que inevitavelmente entram em jogo durante o julgamento sejam levadas em conta exclusivamente em função de sua racionalidade.

Weber estava certo, portanto, ao derivar a legitimidade da lei de sua racionalidade. No entanto, esta não está na universalidade semântica das normas, mas no caráter universal dos procedimentos democráticos que instituem a lei e nos procedimentos jurídicos que distribuem igualmente ônus da prova e necessidades de autojustificação. ${ }^{16} \mathrm{O}$ critério de julgamento da legislação é saber se todos os interessados participaram da elaboração da lei; o critério de julgamento para os procedimentos judiciários é saber se a situação foi corretamente contextualizada. ${ }^{17}$

Esta concepção procedimental da moralidade legitimadora do Direito moderno embasa-se historicamente, na medida em que podemos

${ }^{15}$ Critical Legal Studies (CLS): escola de pensamento juridico que formulou uma severa crítica do sistema jurídico moderno a partir de uma série de estudos empíricos que demonstraram o quão pouco a realidade do sistema jurídico corresponde aos princípios que geralmente são utilizados para legitimá-lo. Para uma comparação entre um autor dos CLS e Habermas, ver Rasmussen (1988).

16Waarscher (1986) sugere que uma forma de tornar menos "idealizada" a discussão jurídica tal como é concebida por Habermas pode ser a utilização da "Nova Retórica" perelmaniana como ponto de partida para a construção da teoria da argumentação que Habermas repetidas vezes afirma necessária para a transposição de sua teoria da comunicação para o estudo de discussões concretas. Aceitando-se ou não a sugestão, o fato é que a ausência de tal teoria fragiliza bastante a teoria habermasiana frente a cíticas que procuram demonstrar a inaplicabilidade da idéia de situação ideal de comunicação à realidade social marcada por antagonismos muitas vezes inconciliáveis.

17Ver a este respeito Apel (1990). 
verificar a passagem de uma moralidade convencional para uma moralidade pós-convencional no rastro da substituição das doutrinas religiosas pelas doutrinas do Direito Natural na justificação do poder político. Estas doutrinas, no entanto, eram elas mesmas bastante carregadas de elementos metafísicos; quando estes sào questionados, somente a forma do contrato, como ela aparece, por exemplo, em Rawls, ${ }^{18}$ resta como momento de legitimação moral e determinação de limites para o exercício do poder - como era a religião na moralidade convencional.

Este momento da indisponibilidade é condição para a separação entre o poder político e a lei. Daí que "Não pode haver Direito autônomo sem democracia" (Habermas, s.d., p.X). Chegamos a um ponto, portanto, em que a preservação da influência do mundo da vida torna-se ela mesma um imperativo sistêmico.

\section{Conclusão: Do Direito à Globalização}

Assim, a análise das Tanner Lectures nos permite relativizar algumas das impressões que a análise habermasiana da juridificação pode ter suscitado. Como vimos, a lei pode e deve ser desformalizada quando isto é condição para a aplicação da moralidade pós-convencional. No entanto, essa mesma moralidade é o limite para esta desformalização, na medida em que se admite que o Direito (democraticamente instituído e pautado pelos princípios da moral procedimental), dado seu caráter de mediação necessária entre sistema e mundo da vida, é também uma garantia da autonomia dos espaços de discussão característicos do mundo da vida.

A noção de Direito ocupa, portanto, um lugar singular e ambíguo na teoria habermasiana: essa ambigüidade parecia ser acentuada pelo fato de que muitos dos casos concretos de juridificação são também casos de

\footnotetext{
18Para um esboço de comparação entre Habermas e Rawls, ver o texto de Berten em Van Parijs (1984).
} 
desformalização (como no caso de programas de assistência a famílias carentes nos Estados Unidos). No entanto, a formulação habermasiana ganha em clareza quando percebemos que a moralidade pósconvencional é a chave para a resolução de um dos problemas mais freqüentemente apontados em Habermas (em especial pelos adeptos do pós-estruturalismo): a tensão entre valores universalistas e direito à diferença. Simpson (1986) coloca a questão nos seguintes termos:

'Muito da preocupafão com o status da particularidade no trabalbo de Habermas centra-se em torno da idéia de que o privilégio dado aos interesses generalizaveis (...) ameaça extinguir a diversidade humana. (...) Essa conclusão seria necessariamente correta apenas se a nofãa babermasiana de interesses generalizáveis necessariamente implicasse um conteúdo substantivo (...) Mas isso é exatamente o que a teoria não permite. Ao invés disso, ele trata de um consenso sobre interesses generalizáveis alcançado sob condições ideais de diálogo, um consenso cujo conteúdo (...) não pode ser afirmado antecipadamente" (Simpson, 1986, p.331). ${ }^{19}$

Um bom exemplo desta idéia seria encontrado no exemplo da desformalização, quando um consenso democraticamente estabelecido (as leis) é modificado frente a um contexto particular:

“(..) algumas vezes uma norma deverá ser revisada para levar em conta um interesse concreto. (...) Se um (...) consenso racional sobre interesses generalizaveis é alterado para acomodar um interesse até então não expresso ou não reconbecido, então esse interesse recém-

19No original: "Much of the concern over the status of particularity in Haberma's work centers about claims to the effect that the privileging of generalizable interests (...) only threatens to wipw out human diversity. (...) This conclusion would necessarily follow only if Haberma's notion of generalizable interests necessarily implied a substantive content (...)But this is just what his theory will not allow. He speaks instead of a consensus over generalizable interests reached under conditions of ideal dialogue, a consensus whose content (...) cannot be stated in advance". 
reconbecido expande nossa visão do que é o bumanamente universal" (Simpson, 1986, p.332-333). ${ }^{20}$

Por outro lado, quando a desformalização não é pautada pelos princípios da moral pós-convencional, ela pode ser interpretada como colonização do mundo da vida, como ação de mecanismos sistêmicos. Um exemplo disto seriam as novas formas de desformalização características do período de declínio do poder de intervenção dos Estados Nacionais e da transnacionalização da economia. Vale, portanto, relembrar a análise habermasiana da crise do Estado de bem estar-social e introduzir alguns de seus comentários recentes sobre a globalização:

Habermas aceita a periodização (genealogia?) do Estado moderno desenvolvida por Kirchmeier: com a crise do feudalismo e a ascensão do mercado, surge primeiro o Estado burguês ou civil em que, sob o absolutismo, instituem-se os princípios do Direito civil. Em seguida, a autoridade do executivo é ela mesma limitada na república constitucional; a esfera pública avança decisivamente com a constituição do estado democrático; em outro estágio, a democracia é instrumentalizada em nome de valores igualitários no sentido de se compensarem as desigualdades sociais produzidas no mercado, e forma-se o moderno Estado de bem-estar social (welfare state). É fácil perceber que o critério que orienta esta classificação não é a análise dos princípios estruturantes do aparato estatal, mas sim as lutas através das quais a moralidade de fundo do estado moderno é instrumentalizada em um ou outro sentido; é uma classificação do ponto de vista do mundo da vida.

Deste ponto de vista, deve-se reconhecer que, se por um lado, o Welfare State representa um avanço dos valores comunitários sobre a

${ }^{20}$ No original: “(...)sometimes a norm will have to be revised in order to take a concrete interest in account. (...). If a (...) rational consensus over generalizable interests is altered to accomodate a theretofore unexpressed or unrecognized interest, then that newly recognized interest expands our vision of the universally human". 
lógica sistêmica, sua estrutura burocrática acaba por minar as bases comunicativas da moral pós-convencional. A crise do welfare state, iniciada na década de 70, poderia ser vista assim como a reação consciente à burocratização provocada pela transferência para o Estado do papel de formação de solidariedade social. É esta a interpretação de Rosanvallon (1981): para este autor, a crise está relacionada fundamentalmente à emergência de valores pós-materialistas. Rosanvallon inclusive inclui em seu programa político um questionamento radical das estruturas do Estado moderno, na medida em que defende a passagem do poder de decisão da burocracia para instituições da sociedade civil, e um Direito que reconheça as identidades coletivas como sujeitos jurídicos.

A princípio, esta análise pareceria perfeitamente compativel com a análise habermasiana precedente. A transferência de poder para a sociedade civil não seria a solução ideal para a questão da juridificação? $O$ Direito coletivo não reconhece a legitimidade de espaços de comunicação extra-administrativos - concretizando institucionalmente a ética do discurso?

Surpreendentemente, a análise habermasiana da crise do welfare state parece ir em uma direção diferente: embora admitindo que sentimentos anti-burocráticos legítimos possibilitaram a aceitação popular do programa de desestatização, e sem jamais esquecer o potencial que a crise do welfare state abre para uma crítica social radicalmente-democrática, Habermas enfatiza que, na luta política que culminou no desmantelamento do sistema de welfare, imperativos funcionais do mercado foram decisivos; aliás, é curioso que $A$ Nova Intransparência (Habermas, 1987) muitas vezes citado como texto-base para compreender a adesão de Habermas à crítica da sociedade do trabalho, nos parece ser bastante marcado por análises de políticas de classe, pelo menos se o comparamos a textos anteriores, como $A$ crise de legitimajãa no capitalismo tardio (Habermas, 1994), bastante mais "sistêmico". Assim, o desmonte do 
sistema de welfare não é uma vitória do mundo da vida e da democracia, mas sim um momento crucial do processo de colonização pelo sistema.

A diferença entre estas duas análises nos parece importante, na medida em que revela uma diferença sutil, mas importante entre os dois autores: em comparação a Rosanvallon, Habermas tende a ser mais universalista. Essa diferença de ênfase permite a Habermas perceber melhor do que Rosanvallon que a crise é basicamente a crise das instrumentalizações do Estado pelos valores comunitários universalistas, únicos capazes de proporcionar uma crítica democrática forte da burocracia.

Certos aspectos da crise do Welfare State podem ser entendidos como momentos de desjuridificação: assim, por exemplo, a desregulamentação das relações trabalhistas. Da mesma forma, o processo de globalização, intimamente ligado à crise do Welfare State, implica em um processo ainda mais forte de desformalização:

“(...) a concep̧ão do direito como um sistema basicamente fechado, bierarquizado e axiomatizado de normas de conduta (...) foi sendo progressivamente substituida pela visão do direito como um conjunto de normas de organização sob a forma de 'rede', dadas as múltiplas cadeias normativas e os micro-sistemas legais, com suas inter-relafõos basilares aptas a capturar, pragmaticamente, a crescente complexidade da realidade sócio-econômica. (...) esse emergente sistema normativo sob a forma de 'rede' se destaca pela multiplicidade de suas regras, pela variabilidade de suas fontes e, principalmente, pela provisoriedade de suas estruturas normativas, que são quase sempre parciais, mutáveis e contingenciais" (Faria, 1996, p.8).

No entanto, o processo é exatamente oposto ao verificado na desformalização causada pelo Welfare State: aqui não se trata de dar uma direção moral à lei, mas sim de libertá-la do conteúdo moral da cidadania nacional expresso na legislação social e nos mecanismos de decisão democráticos. Disso decorre boa parte da resistência ao processo de globalização, que tem sido eminentemente "sistêmico": 
"A comunicação global ocorre tanto por meio de linguagens naturais (na maioria das vezes através de meios de eletrônicos) como por códigos especiais (são os casos, sobretudo, do dinbeiro e do Direito). (...) $O$ crescimento dos sistemas e das redes intensifica a multiplicaf̧ão dos contatos e das informações possiveis; mas não estimula, per se, a expansão de um mundo compartilhado intersubjetivamente. Atualmente, ainda não está claro se a expansão dessa consciência, que depende de intersubjetividades de ordem mais elevada, num universo ainda maior de significados compartilhados, será capaz de abarcar os sistemas ampliados, ou se em vez disso os processos sistêmicos, tendo se autonomizado, irão levar à fragmentação de uma multiplicidade de aldeias globais sem relacionamento entre si"'(Habermas, 1995, p.98).

Não está excluída, obviamente, a possibilidade de se reconstruir a cidadania em nivel global, por mais que isso pareça distante da realidade atual. Devemos reconhecer inclusive que a idéia de globalização tem um potencial universalista. No entanto, talvez não caiba falar de reconstrução neste caso; pois a crise do welfare state traz também uma outra dimensão, bem percebida por Rosanvallon: a de uma crise (bem-vinda) da legitimidade burocrática. $\mathrm{E}$ reconstruir o fenômeno burocrático em nível global - ou como mediação entre as burocracias nacionais - seria uma perspectiva pouco animadora do ponto de vista da democracia. No dizer de Ingram:

"Habermas permanece suficientemente radical para advogar como objetivo meritório a democratização social do local de trabalho, naturalmente desde que compativel com a eficiência da produção. Mas sua desconfiança (à la Arendt) da inclusão marxista do político no econômico - desconfiança nascida da experiência amadurecedora do socialismo burocrático - leva-o a postular uma condição prévia: a reforma do próprio sistema politico"(Ingram, 1987, p.214-215).

Permanece em aberto a questão de se saber se, não se interrompendo o processo de globalização, ele se desenvolverá como universa- 
lismo ou como sistema "puro". Neste último caso, convém lembrar a observação de Habermas de que o sistema precisa estar ancorado no mundo da vida, sob pena de ver sua legitimidade, e, portanto, sua funcionalidade, corroída. Por outro lado, a reemergência de práticas pautadas por moralidades ainda convencionais, e mesmo pré-convencionais - racismo, xenofobia, etc. - pode sugerir que o sistema global pode ser favorecido pelo descarte da idéia de cidadania contida no nacionalismo moderno em favor de elementos moralmente reacionários contidos nesta mesma idéia.

Este é, portanto, um momento de crise da cultura democrática, quando nos vemos diante de configurações econômicas e políticas cada vez mais complexas. Reconhecer a complexidade do mundo contemporâneo e mesmo assim, criar saídas pela radicalização da democracia (visto que tanto a complexidade quanto a democracia têm origem em um mesmo processo de racionalização), é a tarefa que Habermas (concordemos ou não com seu esquema teórico mais geral) se propõe. Ou melhor: nos propõe.

ABSTRACT: Law is a singular conceptual entity inside Habermas' wider theorethical framework: It's a mediation between system and lifeworld; and it's also a privileged access to some theorethical questions wich underlie The Theory of Communicative Action, such as the Welfare State's crisis and the post-structuralist critique of reason. In this article we wish to compare two of Haberma's interventions on juridical discussions: the analysis of juridification in the Theory of Communicative Action and the discussion of deformalization of Law in the Tanner Lectures. We conclude by reaffirming the singularity and the importance of the problematic of Law, and by trying to link this discussion with the debate concerning globalization.

KEYwORDS: Habermas; Law; Juridification; Deformalization; Globalization. 


\section{BIBLIOGRAFIA}

APEL, K. Universal Principles and Particular Decisions and Forms of Life. In GAITA, R., Value and Understanding: Essays for Peter Winch. Londres: Routledge, 1990.

FARIA, J.E. Introdução. In: FARIA, J.E. (org.), Direito e Globalização Econômica: implicajōes e perspectivas. São Paulo: Malheiros, 1996.

FOUCAULT, M. $A$ Verdade e as Formas Juridicas, Rio de Janeiro: Nau, 1996.

HABERMAS, J. Théorie de l'agir Communicationnel. s.l., 1987, Fayard. . A Nova Intransparencia. Novos Estudos CEBRAP, $\mathrm{n}^{\circ}$. 18, São Paulo, setembro de 1987.

. A Crise de Legitimajão no Capitalismo Tardio. Rio de Janeiro:

Tempo Brasileiro, 1994.

. Law and Morality: Two Lectures, não-publicado.

- La desobediencia civil, piedra de toque del estado democrático de derecho. In: Ensayos Politicos. Barcelona: Peninsula, 1988, p.51-72.

. O Estado-Nação europeu frente aos desafios da globalização.

Novos Estudos CEBRAP, n ${ }^{\circ}$.4, São Paulo, novembro de 1995.

INGRAM, D. Habermas e a Dialética da Razão. Brasilia: UNB, 1987.

KELLEY, M. (org.) Critigue and Power. Recasting the Habermas/Foucault Debate. Boston: MIT press, 1994.

RASMUSSEN, D. Communication Theory and the Critique of Law:

Habermas and Unger on the Law. Praxis International, Oxford, vol. 8, $\mathrm{n}^{\circ}$. 2, July 1988.

ROSANVALLON, P. La Crise del'État Providence. Seuil, 1981.

SCHEUERMAN, B. Neumann vs. Habermas: The Frankfurt School and the Rule of Law. Praxis International, Oxford, vol. 8, $\mathrm{n}^{\circ}$. 2, July 1988. 
. The Rule of Law and the Welfare State: Towards a New Synthesis. Politics and Society, vol. 22, Number 2, June 1994.

SIMPSON, L.C. On Habermas and particularity: is there room for race and gender on the glassy plains of ideal discourse? In Praxis International, Oxford, vol. 6, $\mathrm{n}^{\circ} .3$, October, 1986.

Van PARIJS, P. Fondements d'une Théorie de la Justice: Essai critiques sur la philosophie politique de John Rawls. Louvain-la-Neuve, Éditions de l'Institut Supérieur de Philosophie, 1984.

WAARSCHER, G. Perelman and Habermas. Lav and Philosopby, vol.5, $\mathrm{n}^{\circ}$. 3, December 1986.

WEBER, M. A Ética Protestante e o Espirito do Capitalismo. São Paulo: Livraria Pioneira, 1989. 